\title{
La hipótesis de la cinefilia docente. El cine de ficción en la escuela media argentina
}

The hypothesis of teachers' cinephile.

The fiction cinema in the Argentine middle school

Ariel Benasayag ${ }^{1}$

Facultad de Ciencias Políticas y Sociales - Universidad Nacional de Cuyo | Argentina

\section{Resumen}

El artículo examina modos de incorporación pedagógica del cine de ficción por parte de docentes de escuelas argentinas de nivel medio, a partir de datos obtenidos en Escuelas, jóvenes y saberes: una investigación sobre las prácticas de docentes y estudiantes con el lenguaje audiovisual y los nuevos medios (FLACSO/Argentina, 2011). Se revisan prácticas con películas en el aula y supuestos acerca de las posibilidades pedagógicas de las imágenes, considerando tanto articulaciones y tensiones históricas de la relación entre escuela y cine como las particularidades del régimen visual actual. Finalmente, poniendo en relación hábitos de consumo y modos de utilización, se postula que cierto uso escolar de películas responde a un significativo vínculo personal de los docentes con el cine, una cinefilia docente.

Palabras-clave: cine, educación, docente, cinefilia

\section{Abstract}

The article examines ways of pedagogical incorporation of fiction films by teachers of Argentinian Middle Schools, based on data obtained in Schools, youth and knowledge: a research on the practices of teachers and students with audiovisual language and new media (FLACSO/Argentina, 2011). We review practices with films in the classroom and assumptions about the pedagogical possibilities of images, considering both historical articulations and tensions of the relationship between school and cinema as well as the particularities of the current visual regime. Finally, establishing a relation between consumption habits and modes of use, we postulate that a certain school use of films responds to a meaningful personal bond of teachers with cinema, a teachers' cinephilia.

Keywords: cinema, education, teacher, cinephilia

\section{La hipótesis de la cinefilia docente. El cine de ficción en la escuela media argentina}

Primera escena. Entre 1897 y 1900, apenas unos años después de que el cinematógrafo fuera dado a conocer en París por los hermanos Auguste y Louis Lumière, el doctor 
Alejandro Posadas registra en cinta fílmica dos intervenciones quirúrgicas en el Hospital de Clínicas de la Universidad de Buenos Aires. Se trata, según Diana Paladino (2006, p. 136), de películas que resultarían precursoras tanto para la medicina como para la cinematografía y, más acá y más allá de ambas, para la pedagogía: el médico las encarga para enseñar a sus discípulos dos técnicas que él mismo ha desarrollado, produciendo "los que tal vez sean los primeros filmes científico-didácticos con propósito académico de la historia del cine". Tras la muerte del médico en 1902, no hubo continuadores de estas experiencias fílmico-pedagógicas en Argentina.

Segunda escena. Inscripto dentro del normalismo positivista, el pedagogo Víctor Mercante publica en 1925 El cinematógrafo, trabajo en el que afirma sistemáticamente la importancia de este artefacto para la educación. Sin embargo, Silvia Serra (2011, p. 103) observa que del mismo modo que Mercante señala la potencialidad pedagógica del cine, objeta que puede resultar dañino para la psiquis infantil: "el niño se olvida rápido de lo que ha aprendido sin esfuerzo; la sucesión rápida de la imágenes perjudica su fijación en la memoria". La investigación muestra que detrás de la reiterada enumeración de ventajas y desventajas presentes en la literatura de la época (y de toda la primera mitad del siglo) subyacen prescripciones sobre su utilización en el aula y proscripciones fundadas en juicios morales: "Entre los instrumentos escolares la película no representa más que un mapamundi, un mapa en relieve o lápices de colores" (Gunther cit. en SERRA, 2011, p. 96); "Esta excelente escuela de criminalidad y perversión donde relucen dagas, puñales, revólveres, carabinas o a cada momento se trenzan sujetos en feroces explicaciones, imagináosla una escuela común" (Mercante cit. en SERRA, 2011, p. 180).

Tercera escena. "Yo te podría hablar tres horas de Frida Kahlo, pero si te paso la película Frida (Frida, 2002), que está fantásticamente bien hecha, ya está", cuenta enfática Bárbara, docente de Historia del Arte de 47 años. En el marco de la misma investigación sobre la incorporación escolar de imágenes por parte de docentes de nivel medio de escuelas argentinas ${ }^{1}$, Leandro, profesor de Psicología de 48 años, explica entusiasmado que antes de proyectar la película Retratos de una obsesión (One hour photo, 2002) como "un caso para comprender fenómenos psicológicos", menciona a los estudiantes datos de la producción, anécdotas del rodaje e impresiones personales: "Esas cosas yo las marco, primero, porque le dan pasión al contenido, y entonces ya no estamos viendo una película, estamos compartiendo un hecho cultural".

\footnotetext{
${ }^{1}$ La investigación Escuela, jóvenes y saberes: una investigación sobre las prácticas de docentes y estudiantes con el lenguaje audiovisual y los nuevos medios, fue dirigida por la Dra. Inés Dussel y financiada por FLACSO Argentina y Ford Foundation. Realizada en 2011, en la misma se encuestaron 139 profesores y 294 alumnos de 15 escuelas públicas de nivel medio en cuatro jurisdicciones argentinas: Ciudad Autónoma de Buenos Aires, Mar del Plata, Tucumán y Mendoza. Se entrevistaron además 29 docentes y 54 alumnos. El equipo de trabajo estuvo integrado por Inés Dussel, Patricia Ferrante, Delia González, Julieta Montero, Jaime Piracón, Daniela Zampieri y Ariel Benasayag.
} 
Las afirmaciones de estos docentes nos conducen a preguntarnos sobre la incorporación escolar del cine en la escuela argentina contemporánea: ¿qué supuestos sobre las posibilidades pedagógicas del cine subyacen? ¿Qué sobreentendidos, qué matices, qué alcances evidencia la expresión ya está en el primer testimonio? ¿Por qué es significativo compartir una película producida con fines comerciales en tanto hecho cultural en el contexto del aula? ¿Por qué es relevante acercar a los estudiantes al mundo del cine, incluso si para hacerlo debe restarse tiempo a los temas obligatorios del curriculum? ¿Es necesario dar pasión a los contenidos escolares, vinculados al pensamiento racional y crítico? Con todo, la interrogante de fondo surge quizás de la entonación con la que los profesores relatan sus prácticas: la celebración del cine que ambos hacen, leída a luz de las dos escenas históricas previamente descriptas, nos permiten intuir un cambio en la jerarquía de los saberes tradicionalmente legitimados por el discurso pedagógico; o, al menos, postular una ampliación de los mismos en el discurso de los docentes, que no necesariamente coincide con el de la institución escolar.

A lo largo de este artículo reflexionaremos sobre los modos de incorporación del cine de ficción por parte de docentes de nivel medio de escuelas argentinas. En este recorrido, comenzaremos revisando tanto sus prácticas con el cine en el aula como sus supuestos acerca de las posibilidades pedagógicas de las imágenes en general, tomando en cuenta tanto las articulaciones y las tensiones históricas de la relación entre escuela y cine como las particularidades del régimen visual contemporáneo. Luego, poniendo en relación hábitos de consumo cultural y modos de utilización escolar, postularemos la hipótesis de que en ocasiones los usos de películas en el aula responden menos a disposiciones institucionales que a un fuerte vínculo personal de los docentes con el cine, a un modo particular de mirar, reflexionar y difundir el discurso del cine que denominaremos cinefilia docente. Trabajaremos transversalmente la discusión acerca de la mediación pedagógica del cine, oponiendo al supuesto del reduccionismo de la recontextualización didáctica un pensamiento sobre las posibilidades de ampliación de los límites de la cultura escolar y de enriquecimiento de los procesos de interpretación de los estudiantes.

\section{El régimen visual contemporáneo}

A propósito de las articulaciones y tensiones de las relaciones entre escuela y cine a lo largo del siglo XX en Argentina, en un trabajo anterior (2012, p. 8) planteamos que a los ojos del discurso pedagógico "el cine ha sido considerado como símbolo de innovación, instrumento de transmisión cultural, amenaza institucional, dispositivo con potencial pedagógico, peligro moral y puerta de acceso al mundo". En diálogo con los trabajos de Silvia Serra (2011), Diana Paladino (2006) y Ana Abramowski (2009) observamos que

estas concepciones del cine han derivado tanto en exclusiones, regulaciones y adaptaciones como en incorporaciones fundadas en diversos motivos: la enseñanza del 
lenguaje cinematográfico, la crítica ideológica, el aprovechamiento de los aspectos éticos y estéticos, la utilización de su espectacularidad a fin de capturar la atención de los estudiantes. "Usos y representaciones que aparecen de forma simultánea y contradictoria en el discurso pedagógico, y que perduran en las prácticas escolares contemporáneas exhibiendo continuidades, combinaciones y resignificaciones" (BENASAYAG, 2012, p. 8). A propósito de los avatares de este vínculo, Ana Abramowski (2015, p. 1) sostiene que "aun cuando la institución escolar está mayormente identificada como un espacio reactivo al mundo visual (por la primacía otorgada a la palabra escrita), existe en ella una extensa tradición de trabajo pedagógico con imágenes". La autora se ocupa de definir tres tradiciones que actualmente coexisten en la escuela: la de las exclusiones $y$ censuras $^{2}$; la de las inclusiones pedagógicas bajo ciertas condiciones y lógicas de uso; y la de promoción de una mirada crítica. Actitudes que paradójicamente se presentan de forma simultánea exponiendo la complejidad que reviste la relación de la escuela con las imágenes.

En este sentido, a fin de evitar reducir el planteo del problema, Inés Dussel (2014, p. 79) advierte sobre la inconveniencia de realizar una genealogía de las relaciones entre escuela y cine que no tenga en cuenta al mismo tiempo una historia de la visualidad. Entiende que las imágenes -en plural, puesto que resulta problemático hablar de la imagen "como concepto absoluto, sin tener en cuenta los modos en que se la produce y se la apropia o significa en cada época, y que definen qué es y qué produce una imagen" (DUSSEL, 2015, p. 3)-, constituyen prácticas sociales que se apoyan en representaciones icónicas, que se inscriben en una red de relaciones que les dan sentido y que, para el caso de la escuela, nos permiten reflexionar sobre qué produce o qué enseña cierta imagen. En esa red de relaciones, agrega, "hay imágenes y personas, pero también otros objetos, instituciones y tecnologías que intervienen".

Dussel recupera el concepto de regímenes visuales de los estudios visuales para pensar los modos como se produce, circula y se consume lo visual, dentro y fuera de la escuela:

La noción de regímenes visuales ayuda a pensar cómo se organiza el conjunto amplio de imágenes y miradas en una sociedad dada. Nicholas Mirzoeff (2006) destaca que lo visual tiene una historia, que la manera en que vemos y representamos al mundo cambia a través del tiempo, no sólo por las tecnologías disponibles (cuyo rol no es menor en estas transformaciones) sino sobre todo porque lo

\footnotetext{
${ }^{2}$ En un trabajo reciente, Inés Dussel desarrolla una novedosa reflexión acerca de la relación entre iconoclastia y pedagogía a partir del análisis de dos películas infantiles de las década de 1930, abriendo interrogantes sobre "la ambivalencia del gesto iconoclasta en la historia de la pedagogía, como un historia de revuelta y cuestionamiento de autoridades constituidas pero también como un movimiento que permanece atrapado en un círculo (...) generado por la adoración de la imagen prohibida" (DUSSEL, 2017, p. 447).
} 
social mismo es redefinido. El sujeto visual, una condición que todo ser humano comparte, es "una persona que es tanto agente de visión (independientemente de la habilidad biológica de ver) como objeto de discursos de visualidad" (Mirzoeff, 2006, p. 54). En la intersección entre la capacidad de ver y los discursos sociales sobre qué y cómo puede o debe ser visto, se configura un cierto régimen visual que nos convierte en sujetos visuales, que organiza un campo de la visión, una posición de espectador y de espectáculo, que hay que ubicar en la historia [...] En ese acto de ver, importa tanto qué vemos como cómo vemos (DUSSEL, 2015, p. 7).

Antes de examinar las prácticas de incorporación del cine en el aula, cabe entonces detenernos a revisar brevemente las características del régimen visual contemporáneo. Se ha dicho que transitamos el siglo de la pantalla omnipresente y multiforme, planetaria y multimediática (LIPOVETSKY; SERROY, 2009); que habitamos sociedades donde las imágenes han adquirido una centralidad inédita, una cultura global donde su producción, circulación y consumo se extiende de forma inconmensurable y ubicua modificando las prácticas cotidianas y las relaciones sociales. Ya en los '60 Guy Debord (2007, p. 24) anunciaba que la vida social había devenido una "inmensa acumulación de espectáculos", entendiendo al espectáculo no como un mero conjunto de imágenes, sino como una relación social entre personas mediatizada por imágenes: "todo lo que antes era vivido directamente se ha alejado en una representación".

Al respecto, siguiendo a Ana Abramowski (2015, p. 8), resulta significativo destacar algunos rasgos más de este régimen visual: la hipervisibilidad, entendida como la ilusión de una visión total que compulsa a querer registrarlo todo a pesar de que, en tanto régimen de poder, todo régimen visual visibiliza tanto como invisibiliza; la sospecha, en el sentido de que las imágenes han dejado de ser prueba de veracidad: y, finalmente, la expresividad y visibilidad emocional, en referencia al imperativo de "sentir con intensidad" y, al mismo tiempo, exhibir ese sentimiento como un modo de validación del mismo.

¿Cómo es la relación entre escuela y régimen visual? En tanto configuraciones que "contienen elementos políticos, epistemológicos, estéticos, éticos", los regímenes visuales siempre "suponen una pedagogía". Dussel (2015, p. 9) explica que todo régimen visual requiere de saberes que generalmente no están sistematizados si no que "vienen incorporados como protocolos de uso de las tecnologías". En el caso de la escuela, de modos más o menos explícitos, la pedagogía tradicionalmente ha enseñado a mirar 
reflexivamente, a tomar distancia y ha organizado la atención de un modo frontal; esto es, como "una comunidad de espectadores mirando al frente".

Ante este escenario social de visualidades y visibilidades saturadas que obligan a pensar en una nueva economía de la atención también dentro de la escuela, revisaremos el discurso de los docentes respecto de las imágenes en general y del cine de ficción en particular.

\section{El cine en la escuela}

Los datos obtenidos en la investigación Escuelas, jóvenes y saberes muestran que el uso escolar del cine de ficción constituye una práctica frecuente y extendida entre docentes de escuelas argentinas de nivel medio: el 73\% afirma incorporar películas en sus clases, posicionándolas como el tercero de los tipos de imágenes ${ }^{3}$ más utilizados (luego de la fotografía y el gráfico) y el primero entre los formatos audiovisuales. A pesar de que es producido con fines comerciales y de entretenimiento o artísticos, el cine de ficción aparece como el segundo tipo de imagen utilizado con mayor frecuencia por los docentes encuestados, luego de la fotografía. Las respuestas de los estudiantes corroboran estos porcentajes: el $76 \%$ afirma que sus profesores incorporan películas en sus clases, luego del mapa y el gráfico, dos tipos de imágenes propias de la iconografía escolar tradicional. Para leer en perspectiva estos primeros datos cabe recordar que, a pesar de que durante la primera mitad del siglo XX la industria cinematográfica se consolidó y expandió notablemente, el cine de ficción resultó estigmatizado dentro del discurso pedagógico argentino. Según Silvia Serra, esta posición de la pedagogía respondió tanto a la consideración del cine como un "peligro moral" para la sociedad, capaz de ejercer una influencia maléfica sobre niños y jóvenes, como a la conservación del espacio central que la escuela ocupaba en la transmisión cultural, discriminando saberes y prácticas legítimas de aquellas que no los eran (SERRA, 2011). De hecho, el cine fue excluido de los ámbitos educativos hasta las décadas de 1960 y 1970 cuando, tras haber sido reconocido como un arte legítimo en diversos espacios de la cultura, comenzó a ser proyectado en las universidades (PALADINO, 2006).

Por lo tanto, en la postal que delinean los datos, el cine de ficción aparece como el formato audiovisual cuya utilización está más extendida en una gran cantidad de profesores, de los cuales aproximadamente la mitad dice utilizarlo sistemáticamente. A la luz de la historia, podemos interpretar esta tendencia como el indicio de un cambio en la legitimación de saberes al interior del discurso pedagógico: el cine, primer arte de

\footnotetext{
3 En el marco de la investigación Escuelas, jóvenes y saberes se consideraron como tipos de imágenes las siguientes: cine de ficción, cine documental, cómics e historietas, fotografías, gráficos, grafitis y esténciles, mapas, pintura, programas de televisión, publicidad, videojuegos, videos caseros, videos musicales. Se ofreció siempre la posibilidad de agregar otros tipos de imágenes no contemplados en los instrumentos.
} 
consumo de masas, habría comenzado a formar parte de la cultura que merece ingresar y puede ser transmitida dentro la escuela. Lejos de la estigmatización y la exclusión, los profesores actualmente muestran una aceptación generalizada del cine entendido como un saber cultural legítimo y, en muchos casos, realizan una celebración entusiasta de la incorporación pedagógica de películas de ficción.

Sin embargo, a pesar de la aparente contundencia de estas afirmaciones y de que "en la escuela de hoy, la proyección de películas está social e institucionalmente aceptada", advertimos junto a Diana Paladino (2006, p. 139) que esto "no significa que haya logrado la legitimación esperable, pues para algunos proyectar una película en clase todavía suele asociarse con la pérdida de tiempo, el ocio, la nada". En efecto, ni la ampliación de los límites de la cultura escolar hacia ciertos productos de la cultura mediática ni la aceptación manifiesta del uso pedagógico del cine implican directamente una íntegra legitimación institucional y, menos aún, la extensión o diversificación de los tradicionales usos de las imágenes en el aula. Dan cuenta de esto la omisión de estas actividades y de las películas en ellas utilizadas tanto en los programas curriculares como en los proyectos institucionales de las escuelas estudiadas; la precariedad de las condiciones materiales en las que se realizan gran parte de las visualizaciones; el hecho de que la mayoría de los docentes sigue utilizando películas sólo para ilustrar conceptos, motivar o atraer la atención de alumnos "aburridos".

\section{La escuela, los docentes y el cine}

Antes de profundizar en la relación de los docentes con el cine, es pertinente precisar algunos aspectos de la composición del conjunto de profesores que utilizan películas, de sus modos de incorporación en las clases y de las condiciones materiales en la cuales se llevan a cabo estas actividades.

En primer lugar, es significativo mencionar que los docentes que incorporan películas de ficción de modo sistemático aumenta notablemente en las instituciones que atienden a poblaciones de nivel socio-económico medio y medio-alto, en especial en aquellas que poseen programas institucionales orientados a la utilización de imágenes, posicionando al cine como el tipo de imagen más usado en dichas escuelas (67\%). En efecto, la existencia de iniciativas institucionales que promueven la enseñanza de y con imágenes constituye una variable significativa: si bien la utilización desciende en las escuelas que atienden a poblaciones medias-bajas y bajas (40\%), éstas se ubican algunos puntos por encima de aquellas que reciben a sectores medios y medio-altos que no cuentan con este tipo de programas institucionales (33\%).

En relación al género de los docentes no observamos diferencias significativas en el uso del cine de ficción. Sin embargo, sí las advertimos al considerar diferentes segmentos etarios: mientras que sólo el $31 \%$ de los docentes de entre 40 y 49 años dice utilizar 
frecuentemente películas en sus clases, el porcentaje asciende al 51\% para el segmento de 50 años o más, posicionando al cine como el tipo de imagen más utilizado por este grupo. Esta elección podría explicarse considerando que se trata de una generación más vinculada al cine que las posteriores, docentes que vivieron su juventud y se formaron profesionalmente durante la "ebullición cinéfila" de las décadas de 1960 y 1970 (PALADINO, 2006, p. 137), cuando el cine adquirió legitimidad artística y cultural.

Por otra parte, es interesante destacar también que la cantidad de profesores del área de Ciencias Sociales y Humanidades que utilizan frecuentemente películas de ficción (47\%) es superior a la de aquellos que dictan asignaturas de las áreas de Estética y Tecnología (36\%). Esto podría indicar que, en su uso escolar, los aspectos técnicos o estéticos del cine no son tan atendidos ni aprovechados como su dimensión narrativa o su cualidad de representar audiovisualmente el mundo. Como afirma Paladino (2006, p. 138), desde la década de 1980 el uso predominante del cine es aquel vinculado a la "visión ilustrativa", a la posibilidad de plasmar en imágenes lugares geográficos y momentos históricos o reemplazar la lectura de obras clásicas de la literatura.

Por último, la lectura conjunta de dos particularidades de este grupo de docentes permite comenzar a delinear la hipótesis de que la incorporación escolar de películas se vincula con sus hábitos privados de consumo cultural y con concepciones sobre las posibilidades educativas del cine construidas por fuera del discurso pedagógico tradicional. Por un lado, casi el total de los profesores que utiliza películas frecuentemente afirma hacerlo por iniciativa personal, "a partir de sus propias ideas y su formación" (96\%). La incorporación responde entonces a una decisión propia y no una exigencia institucional, ya sea de las autoridades de la escuela, de las coordinaciones de área o de los colegas (es interesante mencionar aquí que un porcentaje significativo dice también incorporar películas a pedido de los estudiantes). Sin embargo, a pesar de que para estos docentes se trata de una decisión personal fundada en su formación, más de la mitad niega haber realizado estudios sobre el uso pedagógico de imágenes (58\%); no mencionan haber cursado materias específicas durante sus carreras ni haber realizado cursos complementarios, ni siquiera aquellos formados en disciplinas estéticas o del campo de la comunicación (BENASAYAG, 2012). Para la mayoría, el saber que moviliza la práctica parece haber surgido de la propia experimentación, vinculada por supuesto a la práctica docente en espacios educativos o a su desempeño profesional en otras instituciones pero, también y sobre todo, relacionada con su propia experiencia como espectadores.

Respecto los modos de incorporación escolar de películas y a propósito de la planificación didáctica de estas actividades, la mayoría destaca la necesidad de rever las películas seleccionadas considerando las particularidades de cada grupo de estudiantes. Agregan que, aquellos que no lo hacen, luego "pierden el tiempo": "Hay profesores que traen la película y la abren acá y se la ponen a los chicos. Para mí eso no sirve para nada [...] ¿Y 
en realidad el chico qué hace? Si le das una película sin algún motivo, es una hora libre" (Marcia, 47 años, Psicología).

Según los profesores el cine suele ser integrado en distintos momentos de la secuencia didáctica, desempeñando así diferentes funciones: aparece tanto como "disparador", introduciendo un nuevo tema o promoviendo la reflexión sobre un problema, como a modo de cierre, permitiendo elaborar conclusiones sobre lo estudiado:

Por ahí en vez de coronar el tema con la película, empiezo el tema y les digo: "En esta película quiero que miren el comportamiento de alguien, que establezcan las diferencias y coloquen aquellas cosas que a ustedes les llame la atención aunque no sepan por qué les Ilama la atención". A veces lo hago con Mejor imposible [As Good as It Gets, 1997], entonces claro, cuando el flaco empieza a caminar así, ellos anotan. $Y$ a raíz de eso empezamos a tratar el trastorno (Marcia, 47 años, Psicología).

El testimonio de Marcia permite observar el modo como las consignas formuladas por el docente de alguna forma condicionan la mirada de los estudiantes frente a la película; la didáctica define la manera como la película debe ser mirada en el contexto de la clase: atendiendo a los personajes, al conflicto, la época representada, la ideología subyacente o simplemente identificando "lo que llama la atención". Esto ha sido criticado por Silvia Serra (2011, p. 290) como una escolarización o disciplinamiento de la mirada: las guías de análisis o la visualización fragmentada e interrumpida direcciona la atención de los estudiantes hacia algunos aspectos de la obra en detrimento de otros, clausurando en última instancia la posibilidad de interpretación libre. Direccionamiento y clausura que impiden que el cine ingrese en la escuela en tanto experiencia cinematográfica; esto es, desplegando lo que le es propio, por impreciso que pueda ser.

Sin embargo, para la mayoría de los docentes estas sutiles reflexiones de orden ontológico o estético sobre el cine suelen pasar desapercibidas, ocupados en aprovechar las potencialidades de las películas para enseñar temas específicos de sus materias (que nunca es Cine o Audiovisual, disciplinas ausentes del curriculum escolar), alejados del consumo de cine en tanto arte. Resulta conveniente entonces matizar aquella crítica, diferenciando distintas prácticas escolares que incluyen películas e intentando identificar lo que el cine puede proponer a la mirada de los estudiantes más allá de cualquier voluntad de disciplinamiento, explícita o implícita.

Aunque entendemos los motivos por los cuales tanto Serra como otros autores (Bergala, 2007) denuncian cierta instrumentalización didáctica del cine, no parece lo mismo ofrecer una visión fragmentada cuando las escenas han sido seleccionadas reflexivamente a fin 
de alcanzar ciertos objetivos pedagógicos, que cuando no se ha calculado la duración del filme y se interrumpe la visualización para dar un recreo. Tampoco resulta idéntico exigir a los estudiantes la realización de un ejercicio oral u escrito respecto de lo visto para conocer su opinión e iniciar un diálogo sobre posibles interpretaciones de la obra, que proyectar una película para evitar malos comportamientos durante la clase, atrayendo la atención de los estudiantes hacia la pantalla.

Seguramente no exista incorporación escolar sin instrumentalización, probablemente tampoco experiencia cinematográfica en el aula sin recontextualización. Sin embargo, el disciplinamiento no necesariamente imposibilita experiencias donde las sensibilidades e interpretaciones de los estudiantes dialoguen con las lecturas propuestas por los docentes y discutan con las de sus compañeros. Tampoco implica que la experiencia cinematográfica, aun siendo diluida en la forma escolar -privada por ejemplo de alguna de sus dimensiones constitutivas, como la oscuridad-, no pueda tener lugar en el aula. Se trata de un aspecto que sin duda requiere mayor investigación, puesto que no sólo esa indecible conmoción estética y ética que en ocasiones producen las películas es lo que hace que el cine sea cine, sino también la visualización colectiva, la situación en la que miramos junto a otros hacia el frente, hacia una misma pantalla, y vemos películas distintas; es decir, el modo como la escuela tradicionalmente ha organizado la visión. Frente al consumo mediático contemporáneo, individualizado y homogéneo, este tipo de encuentro colectivo y plural con una obra y con la opinión del otro, en el que miradas y sensibilidades pueden resultar ampliadas, resulta deseable y necesario.

En este sentido, es importante analizar el rol que cumple el docente en la integración del cine, la mediación que realiza entre la película y los estudiantes. La investigación de Serra (2011) muestra que el discurso pedagógico postula un docente que desempeña el papel de "guía de visualización", acompañando a los alumnos en el abordaje crítico y reflexivo de la obra, "enseñando a ver como se enseña a leer". De nuevo, ante la imposición de una lectura analítica y racional realizada de antemano por los docentes, pareciera que no queda lugar para la interpretación de los estudiantes. Y de nuevo, aunque en otras épocas la pedagogía haya promovido un direccionamiento reduccionista de la mirada, una construcción de un modo de mirar escolar, no podemos afirmar que actualmente esto sea así: en tiempos de saturación y homogeneidad mediática, cuando el modo de mirar de los estudiantes parece ser constituido más en sus propios consumos audiovisuales que a partir de las iniciativas de la escuela, la visualización guiada del docente puede conducir a una ampliación de su mirada. Por parte de algunos profesores la intención está presente:

No explico la imagen, a mí me interesa que ellos me digan. Porque frente a esta cultura visual, también es cierto que hay bastante 
desconocimiento de lo visual. Entonces cuando vos le ponés una obra a un chico y le preguntás "¿Qué ves?", no te lo puede decir. Y me parece que en eso está un poco el trabajo de mediación del docente. Qué ve cuando ve esa imagen, que puede ser cualquiera. El hecho de ver es que él se ponga a pensar qué es lo que está viendo y no es sólo lo que recibe el ojo. Y ahí vos podés empezar a hacer los distintos niveles de lectura de la imagen. Pero les cuesta mucho poder verbalizar qué es lo que ven [...] Entonces, es un proceso. Pero es enseñarles a ver (Bárbara, 47 años, Historia del Arte).

Finalmente, la descripción de la integración escolar del cine no parece estar completa sin la consideración de las condiciones materiales de incorporación en el aula. Al respecto, la mitad de los docentes menciona que el equipamiento le resulta insuficiente para realizar las actividades que se propone; porcentaje que aumenta en escuelas que atienden a poblaciones de nivel socio-económico medio-bajo y bajo, especialmente en aquellas que poseen programas institucionales orientados a la enseñanza de y con imágenes.

En la mayoría de las escuelas a estas dificultades se suman problemas de disposición espacial y organización institucional, que obligan a considerar otras condiciones que la forma tradicional de la escolaridad impone sobre estas prácticas, como las limitaciones de tiempo. Sin embargo, aunque mínimamente, en ocasiones es la propia forma de trabajo escolar la que resulta reconfigurada, adaptada, flexibilizada por la fuerza del cine: "Hay veces que les estoy pasando una película y toca el timbre y se levantan y se van. O sea, ni me preguntan, porque están en su derecho de que cuando toca el timbre pueden salir. $Y$ hay veces que toca el timbre y ni se dieron cuenta y se pasaron viendo la película" (Samuel, 38 años, Lengua y Comunicación Social).

Por último, otra de las demandas de los docentes es que en las escuelas no existen repositorios audiovisuales que contengan películas de ficción, documentales, programas televisivos y ni siquiera videos didácticos que puedan utilizar en sus clases. Más allá de que esto representa otra dificultad, conduce a interrogarnos por las fuentes desde las cuales los profesores toman las películas que proyectan en el aula: para la mayoría se trata de películas "propias, prestadas o alquiladas" (84\%), muchas "obtenidas de Internet". Sólo el 14\% encuentra películas de ficción en la videoteca escolar, que por lo general dispone sólo de algunos documentales. Estos datos refuerzan la hipótesis de que muchos docentes incorporan al aula películas que forman parte de su propio repertorio audiovisual, constituido extraescolarmente a partir de sus consumos culturales cotidianos. 


\section{Supuestos pedagógicos sobre las imágenes y el cine}

Pese a que las condiciones escolares muchas veces resultan poco propicias para la realización de estas actividades, es significativa la cantidad de docentes que incorporan películas en sus clases, incluso cuando en ocasiones son ellos mismos quienes deben llevar al aula sus propias computadoras, parlantes e incluso proyectores para hacerlo. Revisar sus supuestos sobre las potencialidades pedagógicas de las imágenes constituye entonces una posibilidad de comprender más íntegramente estas prácticas, entender qué ponen a jugar en sus clases al momento de incorporar cine de ficción. Hemos visto que para la mayoría existe una fuerte influencia de los discursos pedagógicos tradicionales y de la propia experimentación con el uso educativo de las imágenes. Por el contrario, tienen poco peso los espacios de formación específica o la literatura sobre el tema. Sin embargo, lo que más interesa destacar aquí es el valor que revisten sus hábitos de consumo privado en la conformación de un repertorio audiovisual personal y en los modos de mirar, conmoverse y reflexionar a partir de una película.

En la tercera escena que introduce este artículo nos preguntábamos por los supuestos que subyacen en la afirmación Bárbara, la profesora de Historia del Arte que afirma que si en lugar de "hablar tres horas de Frida Kahlo" proyecta la película Frida (Frida, 2002), ya está. Más adelante, insiste:

\footnotetext{
"Yo te puedo dar cinco clases de Mozart y te puedo hacer análisis de obra y todo lo demás, pero si yo veo Amadeus [Amadeus, 1984), que es una obra espectacular porque hay música, hay una ambientación, hay escenografía, me pinta la época, me da todas las características [...] me parece que depende cómo están contadas las cosas".
}

En su elogio entusiasta sobre ambas películas, Bárbara muestra su convicción sobre que el aprendizaje a partir del cine se produce mágicamente y sin mediación alguna: decimos mágicamente porque la simple y sola exposición a la narrativa cinematográfica resultaría más efectiva para la transmisión de conocimientos que la didáctica tradicional, que ha privilegiado una apropiación racional, la separación disciplinar de saberes, la repetición en el tiempo y la memorización como operaciones de aprendizaje; mágicamente porque permitiría lograr una inmediata e integral comprensión de un fenómeno; mágicamente porque, con todo, pocos docentes pueden explicar claramente lo que les sucede con la imágenes:

Creo que los aprendizajes de las imágenes son lindos porque, en ese sentido, uno no se da ni cuenta de lo que está aprendiendo, y 
que incorporás una estética y una sabiduría que no te das cuenta en ese momento y después por ahí aflora en algún comentario, o en alguna charla o dando clase [...] No es algo práctico o tangible pero sí sirve para la formación del ser humano (Paula, 35 años, Informática).

Para esta profesora de Informática el aprendizaje a partir las imágenes resulta agradable e imperceptible, contribuye al desarrollo de lo propiamente humano y permite desarrollar cierta sensibilidad al tiempo que adquirir una imprecisa sabiduría que pueden emerger espontáneamente. Para Fabiana, docente de Historia y Cultura, Comunicación y Sociedad de 65 años, tampoco se trata de una apropiación consciente sino de una inevitable y duradera inscripción: "[Las imágenes] Enseñan cosas buenas y cosas malas, cosas positivas y cosas negativas. No sé si es enseñanza, pero te deja un seño, una marca". Sus palabras evocan de algún modo el concepto de punctum que Roland Barthes elabora respecto de las fotografías (2003, p. 58): "...sale de la escena como una flecha y viene a punzarme [...] esta herida, esta marca hecha por un instrumento puntiagudo"; y más delante (2003, p. 80): "mueve en mí una gran benevolencia, casi ternura. No obstante el punctum no hace acepción de moral o de buen gusto; [...] puede ser maleducado"; goce o dolor, nunca indiferencia.

Con mayor ingenuidad o iniciación en el pensamiento acerca de las imágenes, los docentes apelan a distintas operaciones con el saber que habilitan y recuperan sus múltiples dimensiones para argumentar sobre sus posibilidades pedagógicas en tanto modos de acceso al conocimiento del mundo y formas de transmisión cultural: su dimensión icónica, su dimensión simbólica, su dimensión narrativa, su dimensión estética; recuperan incluso la propia producción de imágenes mentales, la imaginación entendida como una operación que posibilita un aprendizaje que se puede sentir:

A mí [la forma de acceder al conocimiento] en lo personal me influye [...] Primero yo tengo que volar a través de imágenes, mientras lo estoy leyendo, mientras lo estoy estudiando. Tengo que volar y verlo, digamos [...] Yo creo que cambia el modo de aprenderlo. A través de las imágenes vas a aprender de una determinada manera y a través del texto vas a aprender de otra determinada manera. Aunque el conocimiento sea el mismo (Samuel, 38 años, Lengua y Comunicación Social). 
Samuel señala que la forma determina el contenido y, como otros docentes, explica la relación entre imágenes y conocimiento comparando a las operaciones con el saber que promueven las imágenes con aquellas que permite el lenguaje verbal:

Es muy trillado pero es verdad a veces eso de que una imagen vale más que mil palabras, porque hay imágenes que lo dicen todo [...] Cuando hablás de pobreza -para hablar de algo terrible-, o de hambruna, y ves la foto de una criatura, como criatura tan vulnerable y en un estado de indefensión total, esa imagen para algunos puede valer mucho más que leer tratados que hablan sobre el subdesarrollo o la problemática del hambre, porque esa imagen por lo menos te va a generar que vos te intereses por leer eso, te va a movilizar (Jorge, 47 años, Geografía).

Por supuesto, tal como lo expresa Inés Dussel (2015, p. 11) preguntar qué y cómo enseña una imagen no puede responderse de manera aislada:

No es tanto la imagen en sí lo que causa cierto efecto, sino la imagen en el contexto de culturas o regímenes visuales, de tecnologías, de formas de relación con esas imágenes. Por eso, en la educación y sobre todo en la formación docente, de lo que se trata es de trabajar sobre regímenes visuales que definen lo que es visible y lo invisible, y también modos y posiciones del mirar y del ser visto.

En este sentido, los testimonios de los docentes exhiben esa tensión entre los modos tradicionales de aprendizaje escolar, vinculados al pensamiento racional, analítico, frío y distante, y las formas de acceso al conocimiento posibles al calor de las imágenes: figurativas y sensibles, inmediatas e integrales, agradables y humanistas.

Esto confirma la vigencia de los debates acerca de la jerarquía de las operaciones con el saber dentro del discurso pedagógico, pero deja entrever también cierta declinación de prescripciones tradicionales de la didáctica, un cuestionamiento al curriculum escolar, la flexibilización de formas de la escolaridad que vuelven a ser discutidas:

Yo creo que en el siglo XXI la cultura es de la imagen. Entonces empecemos a sacar horas de Lengua -que cada vez les ponen más a los chicos y cada vez andan peor en Lengua y en Matemática- y empecemos a darles más Arte [...] Porque yo puedo aprender de 
Lengua a partir del Arte y yo puedo aprender Matemática a partir del Arte. Pero están parados en paradigmas históricos donde creen que más horas de Matemática y más horas de Lengua van a hacer que un chico hable mejor, produzca mejor, se comunique mejor, y no es así (Bárbara, 47 años, Historia del Arte).

La jerarquización de las imágenes de la cultura mediática convive en la escuela con argumentos celebratorios y críticas de su centralidad en la época contemporánea: constituye una oportunidad de democratización y legitimación de prácticas y saberes culturales $y$, al mismo tiempo, representa un incesante flujo informacional homogéneo y homogeneizante que pretende espectacularizarlo todo. Estas perspectivas en pugna tienen su correlato dentro del discurso pedagógico, arena de lucha donde las posiciones no carecen de complejidad: no se trataría de recibir la creciente centralidad de las imágenes con un entusiasmo enceguecedor que anule toda posibilidad de análisis reflexivo, pero tampoco de encerrarse en una crítica ciega que sostenga caprichosamente formas de escolaridad que reducen el universo de lo escolar. Es necesario aprovechar la actual revalorización social de las potencialidades educativas de ciertas imágenes para así poder seguir explorando usos y apropiaciones de productos de la cultura mediática; pero reparando en que no sea la propia escuela la que termine arrastrada, arrasada, por ese torrente de imágenes impulsado por una industria que sólo persigue fines comerciales, que es producido para satisfacer gustos estandarizados.

En última instancia, esta discusión conduce a preguntarnos una vez más por la función de la escuela en relación con la transmisión cultural. François Dubet (2006, p. 35) recupera a Émile Durkheim para recordarnos que la escuela debe "arrancar a los actores de la experiencia cotidiana y familiar de su propio mundo". Premisa que Maarten Simons y Jan Masschelein (2014, p. 12) parecen profundizar y ampliar en su defensa de la escuela:

La escuela ofrece "tiempo libre", que transforma los conocimientos y destrezas en "bienes comunes" y, por lo tanto, que tiene el potencial para proporcionar a cada cual, independientemente de sus antecedentes, de su aptitud o de su talento natural, el tiempo y el espacio para abandonar su entorno conocido, para alzarse sobre sí mismo y para renovar el mundo (para cambiarlo de un modo impredecible).

En tiempos de infancias y juventudes que en gran parte aprenden a mirar, a pensar e incluso a sentir a partir de las formas homogéneas y los contenidos uniformes que ofrece 
la espectacularidad de los medios masivos y el bucle algorítmico de las redes sociales digitales, una de las funciones actuales de la escuela quizá deba ser la de ofrecer la posibilidad de acceso a otras imágenes, a otros relatos, a otras sensibilidades.

El cine continúa siendo un medio de expresión capaz de crear una serie de formas que piensan. Frente a un flujo de información basado en la inmediatez y en la redistribución del espacio/tiempo del presente, el cine surge como el medio expresivo que puede proponer la reflexión desde la distancia y la exterioridad. Las películas nos permiten repensar los acontecimientos cuando éstos ya son historia y mirar el presente sin prisas (QUINTANA, 2011, p. 193).

Se trata, como sugiere John Berger (2005, p. 61) respecto de la fotografía de Paul Strand, de que la escuela ofrezca "una manera de ver lugares y personajes cotidianos que amplíe cualitativamente la visión del mundo". La posición de Bárbara, la docente de Historia del Arte, se orienta en esta dirección: el avance de las imágenes, la posibilidad de cuestionar ciertas certezas y tradiciones de la forma escolar, constituyen también la oportunidad de reclamar por la pertinencia y la necesidad del arte como forma de acceso a otro conocimiento del mundo. Al respecto, reconocemos junto a Alain Bergala que:

La escuela, tal como funciona, no está hecha para este trabajo, pero al mismo tiempo, hoy en día es, para la gran mayoría de los niños, el único lugar donde este encuentro con el arte puede producirse. Así pues, está obligada a hacerlo, aun a riesgo de que se tambaleen un poco sus hábitos y su mentalidad. Pues para la mayoría de los niños, si exceptuamos a los "herederos" en el sentido de Bourdieu, la sociedad ya no propone más que mercancías culturales de rápido consumo, rápida caducidad, y socialmente "obligatorias" (BERGALA, 2007, p. 36).

Según Bergala, este encuentro con el arte, con ese otro modo de mirar y conocer, no puede ser enseñado sino que "se encuentra, se experimenta, se transmite por vías diferentes al discurso del saber único $y$, a veces, incluso sin ningún tipo de discurso" (BERGALA, 2007, p. 34). Esta posibilidad de encuentro es la que recuperan los docentes cuando destacan la dimensión emocional del cine, su capacidad de conmover, movilizar, inquietar al espectador; de transmitir lo indecible y lo impensable, de permitir otros modos de acceso al conocimiento. 
La imagen llega a tocar fibras emocionales que no llega a tocar un texto, o una persona que te habla. Yo lo veo cuando, ponele que yo no hubiese visto esta película con los chicos, y entonces se las contaba o hacía un relato por escrito o les daba para leer esa novela: nunca va a ser lo mismo que la imagen del protagonista emocionándose por equis cosa. Llega a otros lados una imagen; a mí al menos las imágenes me emocionan más de lo que me pueden emocionar las palabras, y vengo de ahí, de las palabras (Laura, 31 años, Filosofía).

Este último testimonio resulta significativo también para observar cómo se vinculan los supuestos pedagógicos acerca de las imágenes en general y del cine en particular con las prácticas escolares que despliegan estos docentes. Laura explica la utilización de una película con la que pretende emocionar a los estudiantes apelando a su propia percepción sobre la dimensión emocional del cine. Incorpora el cine en el aula porque es primero ella la que se emociona con la película, en su consumo privado, fuera de la escuela. Y si a ella le sucede (emocionarse y construir así otra relación con el mundo), también puede ocurrirle a los estudiantes. Este indicio nos conduce a interrogarnos sobre los hábitos de consumo cultural de los docentes, sobre sus repertorios audiovisuales y su vínculo personal con el cine. Indagaremos entonces sobre la hipótesis de cierta cinefilia que, en su traslado al aula, podría habilitar nuevas formas de incorporación y apropiación del cine, nuevas articulaciones entre escuela y cultura.

\section{La hipótesis de la cinefilia docente}

En la tercera de las escenas que presentamos al comienzo también nos preguntábamos por las prácticas escolares con el cine a partir del testimonio un docente de Psicología. Leandro parecía querer transmitir a sus estudiantes cierto modo de mirar y pensar el cine, al tiempo que intentaba apropiarse de la dimensión emocional de la narración cinematográfica para dar pasión a los contenidos de su materia. Lo que no mencionamos entonces fue que Leandro se presenta a sí mismo como cinéfilo, un amante del cine.

Tal como hemos postulado, los modos de utilización pedagógica del cine en numerosas ocasiones parecen vincularse significativamente con las propias concepciones sobre las posibilidades educativas de las imágenes en general y el cine en particular, pero también con los repertorios audiovisuales personales, constituidos a partir de prácticas de consumo mediático privadas y extraescolares de los profesores. En otras palabras, comenzamos a observar que una cantidad considerable de docentes que realizan un uso frecuente y sistemático de películas en sus clases, simultáneamente exhiben un fuerte 
vínculo personal con el cine por fuera del ámbito escolar ${ }^{4}$; profesores que deciden proyectar películas a sus estudiantes porque a ellos mismos los han conmovido y de las cuales ellos mismo han realizado algún aprendizaje, relacionado o no con la especificidad curricular. Denominamos a este fuerte vínculo como cinefilia docente (BENASAYAG, 2012), recuperando la definición de Antoine de Baecque y Thierry Frémaux, para quienes la cinefilia no se limita a un consumo regular de cine sino que constituye "una manera de ver las películas, discutir y difundir este discurso" (DE BAECQUE, FRÉMAUX, 1995, p. 134; traducción propia) $)^{5}$.

Podemos comenzar pensando la influencia de los hábitos de consumos privados en la incorporación escolar de películas a partir de un cruce de los datos que arrojó la investigación: el 53\% de los docentes que mira películas de ficción asiduamente, con frecuencia usa el cine en sus clases (14 puntos sobre el porcentaje del resto de las imágenes). Como señalamos oportunamente, otros datos que resultan significativos en este sentido son los referidos a la iniciativa personal manifiesta en la decisión de incorporar imágenes, a la ausencia de formación específica sobre usos pedagógicos de las mismas y a la propia colección como fuente desde la cual los docentes toman las películas que utilizan.

Sin embargo, tal como la hemos definido, la cinefilia de estos docentes puede apreciarse mejor en sus testimonios sobre hábitos, prácticas y rituales en torno del cine que en los datos duros sobre frecuencia de consumo o de utilización escolar. Estos profesores, que se definen a sí mismos como peliculeros o precisamente cinéfilos, están atentos a los estrenos, asisten a salas de cine regularmente, participan de circuitos de exhibición y distribución no tradicionales, leen revistas especializadas, coleccionan obras que les han resultado significativas y vuelven a mirarlas repetidas veces. También disponen de conocimientos sobre la historia, el lenguaje, los géneros o la industria cinematográfica que, en algunos casos, les permiten elaborar argumentos sólidos sobre las películas que han visto (BENASAYAG, 2012). A modo de ejemplo, Bárbara, la docente de Historia del Arte de 47 años, cuenta:

\footnotetext{
${ }^{4}$ Cabe aclarar que si bien la investigación Escuelas, jóvenes y saberes no se enfocó exclusivamente en el consumo personal y el uso escolar de películas, un tercio de los entrevistados manifestó ser "consumidor asiduo" de cine, de los cuales la mayoría expresó además integrarlo en sus clases. Estos datos fueron los que inicialmente despertaron nuestro interés por la reflexión acerca de la relación entre consumos mediáticos y usos escolares, pero además reforzaron los postulados sobre la legitimidad que ha adquirido el cine entre los docentes, quizá por ser considerado un producto de consumo culto.

5 Por supuesto, esta hipótesis no implica la adopción de una posición determinista que considere que las prácticas sociales responden a una única disposición del sujeto; al contrario, consideramos que ellas se producen en relación a una pluralidad de disposiciones, a múltiples lógicas de acción (LAHIRE, 2004). Es decir que, desde nuestra perspectiva, la condición de cinéfilo en un docente no necesariamente implica la incorporación de películas en el aula; del mismo modo, que se usen películas en el aula no siempre responde a este motivo ni genera usos diversos, como en el caso de profesores que sólo consumen películas esporádicamente y que sin embargo generan prácticas novedosas con el cine en el aula. A su vez, todos los docentes desarrollan estas prácticas en un escenario escolar en el que, como hemos visto, se ponen en juego diversas condiciones materiales, múltiples instancias de negociación y un amplio espectro de relaciones entre los distintos sujetos y artefactos.
} 


\begin{abstract}
"Cuando era joven era una cinéfila realmente [...] era cine-arte en esa época, yo me daba unas panzadas infernales. No me gusta el cine comercial, entonces no voy a los "shopping", por ejemplo. Pero sí al cine de la Universidad, que tiene ciclos de películas y de producciones menos conocidas, menos convencionales".
\end{abstract}

Aunque la cinefilia que practican estos profesores dista de ser semejante a la que desarrolló el círculo cercano a la revista Cahiers du Cinéma desde la década de 1950 en París -en el sentido de que aquella era una militancia política a favor del cine que los empujó incluso a manifestarse en las calles-, la definición que proponen de Baecque y Frémaux resulta apropiada para precisar la relación y las prácticas con el cine que llevan a cabo estos docentes: no se trata sólo de un consumo asiduo de cine, sino principalmente de una manera particular de ver películas, de reflexionar sobre las mismas y de apropiárselas para la propia experiencia de vida. Por ejemplo, al conversar con Leandro (Psicología, 48 años) sobre sus prácticas con la cámara fotográfica, el docente cita una frase perteneciente a una película para definir su relación personal con la fotografía: "Es como por ahí dice Robin Williams en Retratos de una obsesión (One hour photo, 2002), que dice 'Es detener el tiempo en algo que merece la pena', que vale la pena detener el tiempo en una foto. Yo coincido muchísimo con eso".

Lo mismo ocurre con Marcia, docente de Psicología de 47 años, cuando, relatando una imagen que persiste en su memoria y vuelve en forma recurrente describe una escena cinematográfica de su repertorio audiovisual, otorgándole un sentido que considera significativo para su propia vida:

Yo soy muy peliculera. ¿Has visto El hombre de la máscara de hierro (The man in the iron mask, 1998)? La imagen de cuando salen los cuatro mosqueteros así y se van a enfrentar con el resto de la [Guardia Real]. Van ellos cuatro, están hechos bolsa los cuatro y viene toda la [Guardia Real] [...] Es esa sensación de decir "Todavía lo intento, todavía puedo".

Por último, en la cinefilia que practican estos docentes también es posible identificar cierta difusión del discurso del cine en el espacio del aula. Los profesores parecen incorporar películas en sus clases con motivos pedagógicos pero además hablan de su pasión por el cine e intentan transmitir a sus alumnos su particular forma de mirarlo y apropiárselo. Estas prácticas pueden promover así una visualización que no se reduce únicamente a los objetivos didácticos, sino que también permite disfrutar de otras dimensiones del cine: en tanto arte, objeto de culto o incluso como entretenimiento. 
Primero la presento, "el director es este, el productor es este, estos son los actores" [...] Les cuento cosas de atrás de la película [Noches blancas; Insomnia, 2002] que me he enterado; que por ejemplo cuando [Robin Williams] tenía que filmar el sangrado de los ojos le andaba salpicando a todos con esa sangre y después el tipo se encerraba 15 minutos y salía con la peor cara de psicótico a filmar esa escena de 10 minutos que tiene. Esas cosas yo las marco, primero, porque le dan pasión al contenido, y entonces ya no estamos viendo una película, estamos compartiendo un hecho cultural [...] Con pibes de escuela técnica, pibes que están todo el día soldando, les fascinaba, no sabés al nivel de análisis que llegaron. ¿Por qué? $\mathrm{Y}$ porque encontraron en mi materia un elemento humano. O sea, iban a hablar de cosas humanas, ya no íbamos a hablar de los circuitos, íbamos a hablar de cosas humanas [...] La imagen termina siendo un elemento integrador (Leandro, 48 años, Psicología).

El testimonio de Leandro ilustra de algún modo lo que hemos dicho pero, como al comienzo, abre nuevos interrogantes. Por un lado, cabe preguntamos por el corpus de películas que los docentes proyectan en el aula y sobre los criterios utilizan para seleccionarlas: ¿qué títulos, qué géneros, qué procedencia tiene las películas que conforman el repertorio audiovisual de los docentes, sean o no cinéfilos? En este sentido, llama la atención que la mayoría de los filmes mencionados en los testimonios pertenezcan a la industria de Hollywood de los últimos veinte años. Los repertorios audiovisuales de estos docentes cinéfilos no parecen estar vinculado al cine-arte, al cine de autor o al cine político como las cinefilias de las décadas de 1960 y 1970; se tratan, en cambio, de una lectura particular en clave humanista, como dice Leandro, del cine industrial.

\section{La deseable mediación docente entre los estudiantes y el cine}

Queda pendiente para un futuro trabajo la pregunta acerca de los estudiantes en relación con el cine, sobre los modos como atienden, se conmueven o aprenden -o ni esto ni aquello- en estas actividades escolares. Sin embargo, nos parece significativo dar un cierre a este trabajo recuperando la discusión que iniciamos algunas páginas atrás sobre la mediación que los docentes establecen entre éstos y el cine.

En los testimonios de estudiantes recopilados en la investigación Escuelas, jóvenes y saberes observamos que, ya sea "dirigiendo la mirada" hacia los objetivos pedagógicos de la materia o instituyéndose en interlocutores que habilitan diálogos y pensamientos a 
partir del cine, los docentes tienen un protagonismo que resulta necesario y enriquecedor en estas actividades: para que los estudiantes puedan acceder a otra imágenes, para que puedan experimentar otros modos de interpretar, para que puedan realizar otras lecturas y construir otros sentidos de las mismas imágenes que forman parte de su entorno audiovisual cotidiano.

Respecto de esta recontextualización del cine en dentro del aula, recuperamos finalmente la revalorización que de ella hace Inés Dussel (2014, p. 81):

La actividad pedagógica no es cualquier actividad: tiene un propósito, establece una secuencia, hace una traducción para un tiempo particular y un espacio particular y requiere que haya agentes y artefactos que se dispongan para llevar a cabo estos objetivos [...] La escuela es la que permite expandir y enriquecer los lenguajes que cada uno trae, y [...] se constituye en una institución importante para la producción de un cultura común y para la organización de la vida pública.

En el contexto de un régimen visual espectacularizado y espectacularizante que se extiende por los flujos continuos e interminables de la imaginería mediática, que funciona saturando visibilidades y homogeneizando visualidades, que compulsa la ilusión de poder verlo todo y desear registrarlo todo en cualquier tiempo y en cada espacio, la capacidad de mediación, traducción, re-presentación de la escuela es bienvenida y resulta, cuanto menos, deseable.

\section{Referencias}

ABRAMOWSKI, A. ¿Cómo mirar, mostrar, sentir y enseñar en un mundo que mira, muestra y siente demasiado? En: Diploma Superior en Educación, Imágenes y Medios, clase $N^{\circ}$ 29. Buenos Aires: FLACSO Argentina, 2009.

ABRAMOWSKI, A. La escuela y su hacer con las imágenes. En: Curso Educación, Cine y Fotografía, Clase No 3. Buenos Aires: Programa Nacional de Formación Docente "Nuestra Escuela" del Ministerio de Educación de la Nación y FLACSO Argentina, 2015.

BARTHES, R. La cámara lúcida. Notas sobre la fotografía. 1ra ed. Buenos Aires: Paidós, 2003.

BENASAYAG, A. El cine de ficción en la escuela argentina. Revisión histórica, hipótesis de trabajo y nuevas interrogantes. En: Revue Ensemble: Revue électronique de la Maison Argentine à Paris, $N^{\circ}$ 8, año 4, mayo, Dossier: Política educativa y dispositivos pedagógicos: transformaciones, usos y efectos. París: Ministerio de Educación de la Nación de la Argentina, 2012. Disponible en: 
http://ensemble.educ.ar/wpcontent/files_mf/dossierarielbenasayagensemble8parapdf.pdf . Acceso en: 24 de mayo de 2017.

BERgALA, A. La hipótesis del cine. Pequeño tratado sobre la transmisión del cine en la escuela y fuera de ella. 1ra ed. Barcelona: Laertes, 2007.

BERGER, J. Mirar. 4ta ed. Buenos Aires: Ediciones de la Flor, 2005.

DE BAECQUE, A. y FRÉMAUX, T. La cinéphilie ou l'invention d'une culture. En Vingtième Siècle. Revue d'histoire, $N^{\circ} 46$, número especial: Cinéma, le temps de l'Histoire, abriljunio. París: Sciences Po University Press, 1995. pp. 133-142.

DUBET, F. El declive de la institución. Profesiones, sujetos e individuos en la modernidad. 1ra ed. Barcelona: Gedisa, 2006.

DUSSEL, I. Imágenes y pedagogía. Algunas reflexiones iniciales. En: Curso Educación, Cine y Fotografía, Clase $N^{\circ} 1$. Buenos Aires: Programa Nacional de Formación Docente "Nuestra Escuela" del Ministerio de Educación de la Nación y FLACSO Argentina, 2015.

DUSSEL, I. La iconoclastia en el cine y la pedagogía. Reflexiones a propósito de dos películas infantiles de los años '30. En: ETD: Educação Temática Digital, v. 19, n. 2, abril/junio 2017. Campinas: Unicamp, 2017. pp. 433-451. Disponible en: https://periodicos.sbu.unicamp.br/ojs/index.php/etd/article/view/8647562. Acceso en: 24 de mayo de 2017.

DUSSEL, I. Usos del cine en la escuela: una experiencia atravesada por la visualidad. En Estudos da Língua(gem), v. 12, n. 1, junio. Número Especial: Memória, Cinema e Linguagem. Vitória da Conquista: Departamento de Estudos Linguísticos e Literários, Universidade Estadual do Sudoeste da Bahia, 2014. p. 77-100.

LAHIRE, B. El hombre plural. Los resortes de la acción. 1ra ed. Barcelona: Bellaterra, 2004.

LIPOVETSKY, G. y SERROY, J. La pantalla global. Cultura mediática y cine en la era hipermoderna. 1ra ed. Barcelona: Anagrama, 2009.

MASSCHELEIN, J. y SIMONS, M. Defensa de la escuela. Una cuestión pública. 1ra ed. Buenos Aires: Miño y Dávila.

PALADINO, D. Qué hacemos con el cine en el aula. En: DUSSEL, I. y GUTIÉRREZ, D. (comp.) Educar la mirada: políticas y pedagogías de la imagen. 1ra ed. Buenos Aires: Manantial., 2006.

QUINTANA, A. Después del cine. Imagen y realidad en la era digital. 1ra ed. Barcelona: Acantilado, 2011.

SERRA, S. Cine, escuela y discurso pedagógico. Articulaciones, inclusiones y objeciones en el siglo XX en Argentina. 1ra ed. Buenos Aires: Teseo, 2011.

\section{Referencias cinematográficas}

Amadeus (Amadeus) Milos Forman, Estados Unidos, 1984. 
Babel (Babel) Alejandro González Iñárritu, Estados Unidos - Francia - México, 2006.

El hombre de la máscara de hierro (The man in the iron mask) Randall Wallace, Estados Unidos - Reino Unido, 1998.

Frida (Frida) Julie Taymor, Estados Unidos - Canadá - México, 2002.

Mejor imposible (As good as it gets) James L. Brooks, Estados Unidos, 1997.

Noches blancas (Insomnia) Christopher Nolan, Estados Unidos - Canadá, 2002.

Retratos de una obsesión (One hour photo) Mark Romanek, Estados Unidos, 2002.

\footnotetext{
${ }^{1}$ Licenciado en Comunicación Social (UNCuyo), diplomado en Educación, Imágenes y Medios y en Gestión de las Instituciones Educativas (FLACSO/Argentina). Fue becario de posgrado de CONICET (2009-2014) y está escribiendo su tesis de doctorado sobre la incorporación pedagógica del cine de ficción en la escuela media argentina. Es Jefe de Trabajos Prácticos del Seminario de Informática y Sociedad de la UNCuyo y Profesor Titular de Semiótica Visual y de Arte Cinematográfico Publicitario en la UMaza, donde además dirige la Licenciatura en Realización Audiovisual. Trabajó en el Archivo Fílmico Pedagógico "Jóvenes y Escuelas" y fue docente del curso Educación, cine y fotografía: estrategias para trabajar con imágenes en la escuela secundaria (PNFD, Ministerio de Educación, 2015).
}

Enviado em: 06 de junho de 2017.

Aprovado em: 13 de julho de 2017. 